\title{
Estado do conhecimento da pesquisa brasileira sobre disciplinas de conteúdo matemático na Licenciatura
}

\author{
State of knowledge of Brazilian research on \\ mathematical contents disciplines in teacher education
}

\author{
Amanda Larissa de Almeida \\ Eliane Matesco Cristovão ${ }^{2}$
}

\begin{abstract}
Resumo
Este artigo apresenta parte de uma pesquisa do estado do conhecimento que mapeou as pesquisas brasileiras sobre disciplinas de conteúdo matemático na Licenciatura e visa analisar como estas contribuem para compreender o campo da formação inicial. Inicialmente, é apresentado um panorama geral do estudo, tendo por base a análise de um corpus de 15 estudos obtido a partir do projeto "Mapeamento e Estado da Arte da pesquisa brasileira sobre o professor que ensina matemática". Em seguida, são analisadas nove teses e dissertações relativas à categoria dos trabalhos que investigaram propostas ou práticas inovadoras. A discussão dos resultados aponta contribuições em relação às abordagens metodológicas adotadas, destacando o uso das tecnologias e a participação dos discentes em práticas colaborativas, investigativas e reflexivas. Entretanto, o estabelecimento de relações entre os conteúdos ensinados e aqueles que o licenciando futuramente irá ensinar revela-se ainda pouco presente nas licenciaturas.
\end{abstract}

Palavras-chave: Formação inicial de professores; Formação matemática; Disciplinas de conteúdo matemático; Estado do conhecimento.

\begin{abstract}
This article presents part of a research on the state of knowledge that mapped Brazilian research on Mathematical content disciplines in the Teacher Education and aims to analyze how they contribute to understand the field of initial formation. Initially, a general overview of the study is presented, based on the analysis of a corpus of 15 studies obtained from the project "Mapping and State of the Art of Brazilian research on the teacher who teaches mathematics". Next, nine theses and dissertations related to the category of works investigating innovative proposals or practices are analyzed. The discussion of the results point to contributions in relation to the methodological approaches adopted, highlighting the use of the technologies and the participation of the students in collaborative, investigative and reflexive practices. However, the establishment of relationships between the taught contents and those that the future licentiate will teach is still not very present in the degrees.
\end{abstract}

Keywords: Initial training of teachers; mathematical training; Disciplines mathematical content; State of knowledge.

\footnotetext{
${ }^{1}$ Licenciada em Matemática pela Universidade Federal de Itajubá e mestranda do Programa de Pós-Graduação em Educação Matemática da Universidade Estadual Paulista (Unesp). Brasil. E-mail: amandalaah95@gmail.com.

${ }^{2}$ Doutora em Educação pela Universidade Estadual de Campinas e professora adjunta do Instituto de Matemática e Computação da Universidade Federal de Itajubá (Unifei). Brasil. E-mail: limatesco@unifei.edu.br.
} 


\section{Introdução}

Nos últimos anos, diversas pesquisas têm se preocupado em investigar a formação matemática do professor que vai lecionar essa disciplina na Educação Básica (Fiorentini, 2005; Moreira \& David, 2005; Manrique, 2009; Grilo et. al, 2015). Estas pesquisas denunciam um distanciamento entre a Matemática que é ensinada nos cursos de graduação e aquela que o licenciando, futuro professor, precisa saber para ensinar.

Os conteúdos matemáticos presentes na Licenciatura têm sido ensinados de maneira formal e muitas vezes em disciplinas comuns com alunos do bacharelado, sem que seja estabelecida alguma relação com a prática docente do professor. E ainda, os conteúdos matemáticos da Educação Básica, quando considerados na formação, são apenas revisados, não proporcionando ao licenciando uma reflexão sobre seu ensino (Moreira \& David, 2005; Grilo et. al, 2015).

Esta problemática nos levou a indagar que tipo de trabalho pode ou deve ser realizado no âmbito das disciplinas de conteúdo matemático para que estas possam contribuir efetivamente para a atuação do futuro professor. Este foi o subtema por nós investigado na segunda fase do projeto "Mapeamento e Estado da Arte da pesquisa brasileira sobre o professor que ensina Matemática", desenvolvido na Faculdade de Educação (FE) da Universidade Estadual de Campinas (Unicamp). Em sua primeira fase o projeto mapeou e analisou 858 teses e dissertações, realizadas no período de 2001 a 2012, produzindo um ebook (Fiorentini, Passos \& Lima, 2016) que apresenta as principais tendências das pesquisas, seus focos e contextos, além de lacunas que indicaram temáticas específicas a serem investigadas nesta segunda fase.

Assim, a pesquisa apresentada neste artigo tem por objetivo, de um lado, mapear e descrever as pesquisas brasileiras que tomam como foco de estudo as disciplinas de conteúdo matemático dos cursos de licenciatura e, de outro, analisar e discutir como elas têm contribuído para compreender o campo da formação inicial, sendo norteada pela seguinte questão de investigação: Que indícios trazem estas pesquisas sobre o modo como as disciplinas de conteúdo matemático são desenvolvidas, tomando como referência a prática profissional efetiva dos professores da educação básica?

Para atingir o objetivo proposto, nos apoiamos nos pressupostos da pesquisa qualitativa do tipo "Estado do Conhecimento" (Ferreira, 2002), utilizada quando se quer ter conhecimento acerca da totalidade de trabalhos produzidos numa determinada área, e na qual o pesquisador "é movido pelo desafio de conhecer o já construído e produzido, para depois buscar o que ainda não foi feito" (Ferreira, 2002, p. 259). Neste tipo de pesquisa, é necessário analisar dados e informações de um conjunto de produções (definidas de acordo com o objetivo da pesquisa) a partir de critérios pré-determinados, de modo que, ao apresentar e discutir o assunto, traga possíveis contribuições para a continuidade de pesquisas no campo investigado. 
DOI: http://dx.doi.org/10.20396/zet.v25i3.8649991

Para delimitar o corpus desta pesquisa tomamos como ponto de partida os textos produzidos para o e-book (Fiorentini, Passos e Lima, 2016), no qual haviam indicações de trabalhos relacionados a disciplinas específicas da formação inicial, e em uma planilha geral que listava informações gerais dos trabalhos (título, ano, instituição, orientador etc), ambos produzidos na primeira fase do projeto nacional anteriormente citado.

$\mathrm{Na}$ planilha geral do mapeamento, checamos se outros trabalhos ainda poderiam compor o corpus. O critério utilizado neste caso foi a leitura de todos os títulos, buscando encontrar palavras que se referiam a disciplinas de conteúdo específico como: cálculo, geometria, álgebra, etc. Após o refinamento destas buscas, a partir da leitura de resumos e trabalhos completos das pesquisas, constituiu-se um corpus de 15 trabalhos.

Para apoiar nossas análises, adotamos um referencial teórico sobre formação inicial de professores de Matemática (Fiorentini, 2005; Passos et. al., 2006) e sobre formação matemática do professor (Moreira \& David, 2005), apresentado a seguir.

\section{A formação do professor de matemática e a formação matemática}

São muitas as concepções que servem de base para a análise dos saberes profissionais docentes (Moreira \& David, 2005) e elas devem ser resultado da reflexão sobre a formação que se procura proporcionar. Deste modo, considerando que o objetivo principal das licenciaturas é formar professores para atuar na Educação Básica (Brasil, 2015), se faz importante uma reflexão sobre os conhecimentos que precisam ser privilegiados no período da formação inicial.

Moreira e David (2005) investigaram que matemática deve o professor de Matemática estudar, problematizando a dicotomia entre a Matemática Acadêmica e a Matemática Escolar. Para os autores, a primeira representa um corpo científico de conhecimento, concebido e produzido pelos matemáticos, e a segunda representa um conjunto dos saberes "validados" socialmente e associados especificamente ao desenvolvimento do processo de educação escolar básica em Matemática.

Diante dessas diferenças, os autores discutem a necessidade de um redimensionamento da formação matemática na Licenciatura, de modo a equacionar os papéis dessas diferentes formas de conhecimento matemático, destacando que a formação matemática,

ao adotar a perspectiva e os valores da Matemática Acadêmica, desconsidera importantes questões da prática docente escolar que não se ajustam a essa perspectiva e a esses valores. As formas do conhecimento matemático associado ao tratamento escolar dessas questões não se identificam - algumas vezes chegam até a se opor - à forma com que se estrutura o conhecimento matemático no processo de formação (MOREIRA; DAVID, 2005, p. 103).

Da maneira como os currículos são organizados, há uma hipervalorização da Matemática Acadêmica, desconsiderando o contexto educativo em que as práticas 
DOI: http://dx.doi.org/10.20396/zet.v25i3.8649991

matemáticas se desenvolvem na Educação Básica, assim como seu papel, aspectos estruturais e diferentes formas de representação dos conceitos.

Ainda para os autores, não se trata de pensar o processo de formação do professor a partir da lógica da prática escolar, mas reconhecer que existe uma tensão entre a Educação Matemática escolar e a Matemática Acadêmica elementar e a partir deste reconhecimento, desenvolver uma concepção de formação matemática do professor, tendo como referência a prática profissional efetiva dos professores na Educação Básica.

Essa concepção é reconhecida pelas Diretrizes Curriculares Nacionais para a formação inicial (BRASIL, 2015) quando asseguram que durante todo o processo de formação deve ser garantida "efetiva e concomitante relação entre teoria e prática, ambas fornecendo elementos básicos para o desenvolvimento dos conhecimentos e habilidades necessários à docência” (p.11).

Fiorentini (2005) destaca que o professor não ensina apenas conteúdo. Ele ensina também - mesmo que não queira - um modo de ser professor e de conceber e tratar a Matemática e seu ensino. Esta é a principal razão pela qual entendemos que as disciplinas de conteúdo matemático têm grande influência na prática docente do professor que está sendo formado e, por isso, a importância e a necessidade dessas disciplinas serem investigadas e problematizadas.

Passos et. al. (2006) realizaram um estudo meta-analítico sobre pesquisas que haviam tomado como foco o desenvolvimento profissional de professores de Matemática. Das onze pesquisas analisadas pelos autores, cinco referiam-se a contextos de práticas coletivas, especialmente as colaborativas, envolvendo professores de diferentes níveis de atuação. Após evidenciar as descobertas de cada um dos cinco trabalhos, os autores afirmaram que

Em todos esses trabalhos, a reflexão compartilhada foi considerada como prática promotora de desenvolvimento. Os resultados apontaram que as tensões vivenciadas no grupo produzem a (re)significação de saberes e práticas e que os processos de reflexão promovem a tomada de consciência dos processos de aprendizagem; revelam o caráter formativo de algumas práticas de sala de aula; ampliam e enriquecem a aprendizagem e os saberes docentes. (PASSOS et. al., 2006, p. 202)

Assim, a partir da análise destes contextos colaborativos de formação de professores, os autores apontam que "as práticas reflexivas, investigativas e colaborativas em ambientes coletivos de aprendizagem docente constituem uma poderosa tríade catalisadora do desenvolvimento profissional dos professores de Matemática” (p. 215).

Apoiados em Nunes (2001), os autores apontam que desde a década de 1990, diante de uma mudança paradigmática na formação de professores e na forma de investigá-la, as pesquisas passaram a reconhecer a "complexidade da prática pedagógica e dos saberes docentes" e a considerar a formação de uma perspectiva que vai "além da acadêmica, envolvendo o desenvolvimento pessoal, profissional e organizacional da profissão docente" (Nunes, 2001, apud Passos et. al., 2006, p. 196). 
DOI: http://dx.doi.org/10.20396/zet.v25i3.8649991

Para tentar mostrar como esta complexidade vem sendo tratada nas pesquisas sobre disciplina de conteúdo matemático, a seguir, inicialmente apresentamos aspectos gerais, seguidos de uma descrição e análise das teses e dissertações identificadas.

\section{Panorama geral das pesquisas}

Os 15 trabalhos que compõem o corpus estão dispostos no Quadro 1 a seguir, separados de acordo com o estado de origem.

Quadro 1- Distribuição por estado das pesquisas que compõe o corpus.

\begin{tabular}{|c|c|c|c|c|c|}
\hline Estado & São Paulo & Minas Gerais & Paraná & Ceará & Total \\
\hline Autores & $\begin{array}{l}\text { Costa (2007); } \text { Freitas } \\
\text { (2006); Marin (2009); } \\
\text { Martines (2012); Mondini } \\
\text { (2009); Moreno (2010); } \\
\text { Reis (2001); Resende } \\
\text { (2007) e Richt (2005). }\end{array}$ & $\begin{array}{l}\text { Campos }(2007), \\
\text { Gonçalves }(2012), \\
\text { Procópio (2011) e } \\
\text { Santos (2011) }\end{array}$ & $\begin{array}{l}\text { Bolognesi } \\
\text { (2006) }\end{array}$ & $\begin{array}{c}\text { Pinheiro } \\
\text { (2008) }\end{array}$ & \\
\hline Total & 9 & 4 & 1 & 1 & 15 \\
\hline
\end{tabular}

Fonte: Elaborado pelas autoras.

No período delimitado, percebe-se que as disciplinas de conteúdo específico em matemática vêm sendo tomadas como foco de forma mais recorrente a partir de 2006, embora, conforme Quadro 2, não haja indícios de um crescimento expressivo.

Quadro 2- Linha do tempo de produção das pesquisas no período de 2001 a 2012.

\begin{tabular}{|c|c|c|c|c|c|c|c|c|c|}
\hline Ano & 2001 & 2005 & 2006 & 2007 & 2008 & 2009 & 2010 & 2011 & 2012 \\
\hline QUANTIDADE & 1 & 1 & 2 & 3 & 1 & 2 & 1 & 2 & 2 \\
\hline
\end{tabular}

Fonte: Elaborado pelas autoras.

As teses ou dissertações foram produzidas, como mostra Quadro 3, em 9 Universidades $^{3}$, sendo 4 delas, localizadas em São Paulo (SP) e que abarcam 9 trabalhos. Dentre elas, a Universidade Estadual Paulista (UNESP) campus de Rio Claro/SP foi a que apresentou o maior número de pesquisas.

Quadro 3- Distribuição das pesquisas por Instituição de Ensino Superior (IES)

\begin{tabular}{|c|c|c|c|c|c|c|c|c|c|}
\hline Estado & \multicolumn{4}{|c|}{ SP } & \multicolumn{3}{c|}{ MG } & PR & CE \\
\hline IES & UNESP & PUC & UNICAMP & USF & UFOP & UFU & UFJF & PUC & UECE \\
\hline QUANTIDADE & 4 & 2 & 2 & 1 & 2 & 1 & 1 & 1 & 1 \\
\hline
\end{tabular}

Fonte: Elaborado pelas autoras.

Dentre os 15 trabalhos analisados, temos 8 dissertações de mestrado acadêmico, 4 dissertações de mestrado profissional e 3 teses de doutorado. Estas pesquisas se dividem entre

\footnotetext{
${ }^{3}$ Pontifícia Universidade Católica (PUC), Universidade Estadual de Campinas (UNICAMP), Universidade São Francisco (USF), Universidade Federal de Juiz de Fora (UFJF), Universidade Federal de Uberlândia (UFU), Universidade Federal de Ouro Preto (UFOP) e Universidade Estadual do Ceará (UECE).
} 
DOI: http://dx.doi.org/10.20396/zet.v25i3.8649991

pesquisas de campo e pesquisas teórico/bibliográficas, todas apresentando em comum a abordagem metodológica qualitativa.

Após uma leitura cuidadosa destes trabalhos, percebemos a recorrência de alguns focos de estudo, assim identificamos duas categorias de análise: (I) Concepções de formadores, professores e futuros professores sobre disciplinas de conteúdo específico e (II) Caminhos para uma formação matemática por meio de propostas ou práticas inovadoras em disciplinas de conteúdo matemático. O Quadro 4, a seguir, apresenta uma divisão destes trabalhos em relação às disciplinas investigadas e à categoria que pertencem.

Quadro 4- Distribuição dos trabalhos por disciplina e categoria de análise

\begin{tabular}{|c|c|c|}
\hline DISCIPLINA/CATEGORIA & CONCEPÇÕES & CAMINHOS \\
\hline Álgebra Linear & Mondini (2009) & \\
\hline Análise Matemática & $\begin{array}{c}\text { Bolognesi (2006) } \\
\text { Martines (2012) } \\
\text { Reis (2001) }\end{array}$ & \\
\hline Cálculo & Marin (2009) & Gonçalves (2012) \\
\hline Estatística & Costa (2007) & Moreno (2010) \\
\hline Geometria Analítica & & Santos (2007) \\
\hline $\begin{array}{c}\text { Geometria Plana e/ou Espacial } \\
\text { e/ou Desenho Geométrico }\end{array}$ & & Richit (2005) \\
\hline Teoria dos Números & & Freitas (2006) \\
\hline
\end{tabular}

Fonte: Elaborado pelas autoras.

Neste artigo, optamos por apresentar apenas a análise dos estudos relativos à categoria "caminhos", composta por nove trabalhos que investigaram propostas ou práticas inovadoras, tendo como referência a prática profissional dos professores.

\section{As pesquisas que apresentam possíveis caminhos para o desenvolvimento de disciplinas de conteúdo matemático}

Dentre as pesquisas analisadas nesta categoria, algumas contribuem com reflexões e compreensões sobre a matemática que pode ser ensinada nas disciplinas de matemática, apresentando e analisando propostas de trabalho relacionadas ao uso de tecnologias digitais, à problematização ou à discussão de problemas etc. Outras pesquisas apresentam e analisam caminhos alternativos de ensino de disciplinas de matemática, propiciando, em nosso entendimento, sugestões e compreensões sobre como as disciplinas podem ser desenvolvidas de forma a contribuir para a formação do professor de matemática.

Analisaremos estes trabalhos separadamente, classificando-os nestas duas subcategorias, mas é importante ressaltar que embora elas não sejam totalmente dissociadas, evidenciam diferentes contribuições. Inicialmente apresentamos uma descrição geral de cada trabalho, para em seguida apresentar uma síntese dos resultados, em cada subcategoria. 
DOI: http://dx.doi.org/10.20396/zet.v25i3.8649991

\section{(a) Foco na Matemática a ser ensinada}

No contexto da disciplina Estatística, Moreno (2010) estudou as características de atividades que favoreçam a apreensão da variabilidade em um conjunto de valores e para isto, desenvolveu uma sequência didática com um grupo de 17 alunos de licenciatura. A sequência foi elaborada segundo a proposta de construção de cenários de aprendizagem e composta por 43 atividades divididas em sete partes: Introdução à média; Medidas-resumo de tendência central, quartis e variabilidade; reflexões sobre a média e sobre a variação dos dados; reflexão sobre o uso da média e a amplitude como medida de Variação; insuficiência da amplitude como medida de variação; a busca de um instrumento mais abrangente; o papel do desviopadrão na criação de intervalos para análise e o desvio-padrão e evento raro.

De acordo com o pesquisador, as atividades estavam articuladas, de modo que os conhecimentos já incorporados fossem mobilizados para construção de conceitos novos a partir de situações problemas que não estavam necessariamente ligadas a conteúdos previamente estudados. Em cada bloco de situações, acontecia uma discussão com toda a turma e, pautado nessa interação, institucionalizava-se o que foi aprendido. Ou seja, os alunos interagiam com o problema sem saber qual conceito o professor queria lhes ensinar. A resposta considerada mais conveniente para solucionar o problema era o conceito a ser formalizado. Na Figura 1 apresentamos dois exemplos de tarefas.

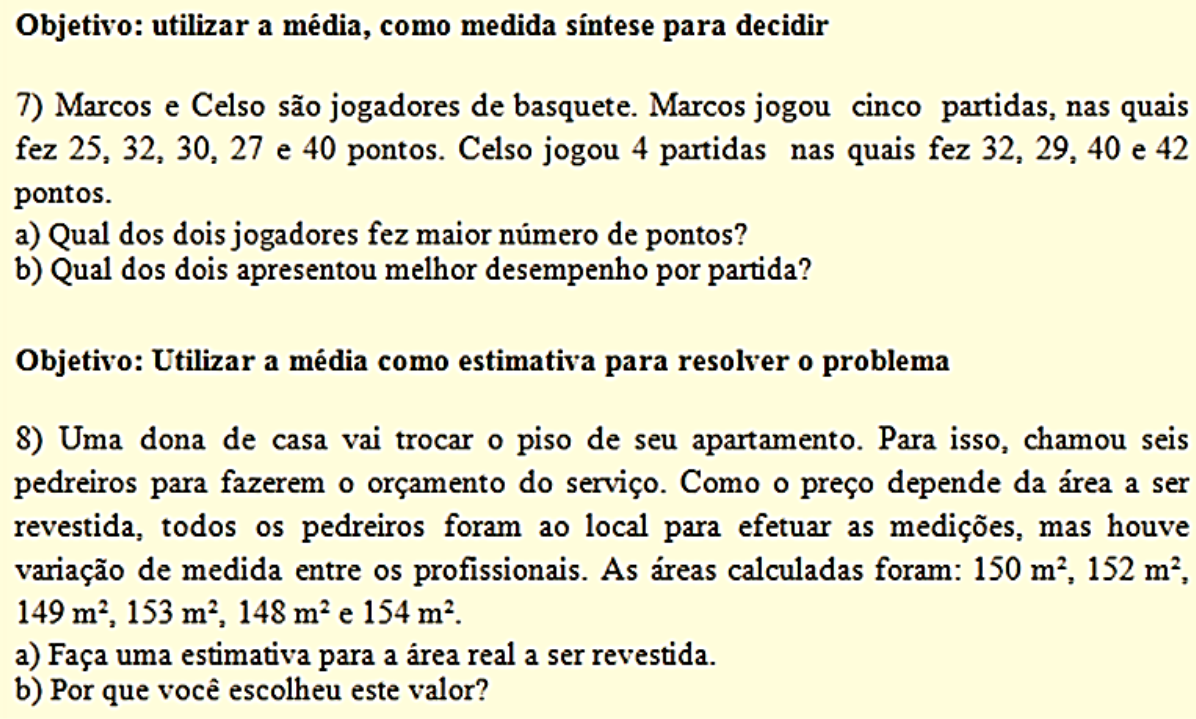

Figura 1: Exemplo de atividades envolvendo o conceito de média.

Fonte: Moreno (2010, p.119-120)

Adotou-se a dinâmica do trabalho em grupo para propiciar a cooperação, a troca de ideias e o debate em torno das propostas de solução das questões. Os licenciandos deveriam apresentar suas sugestões, defender suas posições, ouvir as críticas dos colegas e juntos formular a solução. Nestes momentos, coube ao formador destacar alguns pontos que considerava relevantes para a noção trabalhada, fazer certos questionamentos a respeito dos aspectos do problema que não foram apreendidos pelos alunos e incentivar o debate. 
DOI: http://dx.doi.org/10.20396/zet.v25i3.8649991

Procópio (2011) buscou identificar que características deve apresentar uma disciplina de geometria direcionada para a Licenciatura. Para isso desenvolveu, durante um ano letivo, as disciplinas de Geometria Plana e Geometria Espacial, com foco nos processos de ensino e aprendizagem em Geometria e na formação profissional do Professor de Matemática. A proposta visou incentivar os diferentes modos de produção de significados em sala de aula, especialmente em relação às questões de visualização e de representação gráfica, utilizando a resolução de problemas como dinâmica de ensino e evitando a abordagem axiomáticodedutiva, além de não se restringir ao estudo geometria euclidiana e estimular o uso do desenho geométrico como parte dos argumentos nas demonstrações.

As aulas frequentemente começavam com problemas para causar estranhamento, questionamentos, promovendo debates entre os alunos, de modo que eles atribuíssem diferentes significados que eram negociados e problematizados. Além disso, eram recorrentes tarefas individuais e discussões em grupo nas quais os alunos trabalhavam com representação gráfica e utilizavam a escrita para argumentar.

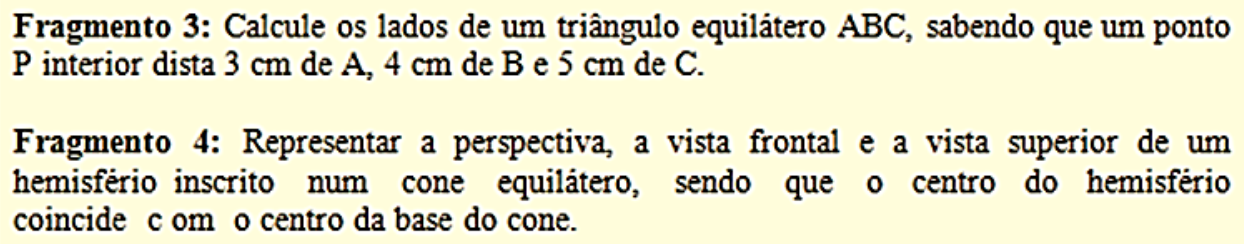

Figura 2: Exemplos de problemas propostos

Fonte: Procópio (2011, p.48)

O pesquisador destaca que na dinâmica adotada "não é o professor quem resolve o problema, são os alunos que a partir de suas crenças-afirmações, de suas justificações, vão produzindo conhecimento e encaminhando a resolução" (p.59). Como resultado, Procópio (2011) aponta que a abordagem metodológica exclusivamente expositiva, não é o caminho para a formação de futuros professores, sendo necessárias estratégias diversificadas, trabalho em grupo, discussão e problematização, de modo a estimular a produção de significado pelo aluno e seu envolvimento com o que está aprendendo.

Em sua pesquisa, Santos (2011) propôs-se a discutir o ensino de Geometria Analítica Plana na perspectiva da Educação Matemática nos Ensinos Médio e Superior, visando contribuir para a formação de futuros professores de matemática. Para isso desenvolveu atividades exploratórias utilizando o software GeoGebra com alunos da licenciatura, explorando os conceitos de reta, circunferência e cônica. O objetivo foi propiciar a exploração, argumentação, questionamento, dedução de definições ou equações e principalmente, a discussão entre os licenciandos sobre os objetos explorados. A figura 3 mostra parte de uma das atividades. 
DOI: http://dx.doi.org/10.20396/zet.v25i3.8649991

\begin{abstract}
Explorando a excentricidade de uma elipse
OBJETIVO: Investigar / conjecturar / deduzir as propriedades da excentricidade de uma elipse

a) Utilizando a barra de ferramentas, vamos clicar no $7^{\circ}$ botão e, em seguida, em "Elipse". Agora, vamos selecionar como focos dois pontos quaisquer do eixo $\mathrm{x}$ e depois movimentar gerando várias elipses. $O$ que você observa sobre o formato dessas elipses?

b) Agora, vamos clicar com o botão direito do mouse sobre uma das elipses, se lecionar "Habilitar Rastro" e movimentar, para verificar a validade de suas observações do item anterior.

c) Tentando fazeruma conexão com o que estudamos na sala de aula, o que você pode concluir em relação à excentricidade das elipses?

d) Utilizando a barra de ferramentas, vamos clicar no $7^{\circ}$ botão e, em seguida, em "Elipse". Agora, vamos selecionar como focos dois pontos quaisquer do eixo y e depois movimentar gerando várias elipses. Vamos fazer as mesmas observações anteriores!
\end{abstract}

Figura 3: Parte de uma atividade desenvolvida

Fonte: Santos (2011, p.153)

O pesquisador discute que o ensino da Geometria Analítica, mediante utilização do software GeoGebra contribuiu para a constituição de um ambiente capaz de privilegiar as ações dos alunos na construção do conhecimento matemático, proporcionando ricas possibilidades de visualização de conceitos e propriedades, privilegiando a experimentação e enfatizando a interpretação de construções geométricas que são difíceis de serem trabalhadas em sala de aula. Além disso, conclui que esse tipo de vivência estabelece uma ponte entre a formação inicial do professor e o ensino médio, à medida que o futuro professor recria uma concepção de ensino e o uso da tecnologia nas aulas de Matemática, podendo adotar essa prática ao ensinar Geometria Analítica aos seus alunos.

Gonçalves (2012), por sua vez, buscou compreender as contribuições de atividades investigativas com o uso das Tecnologias da Informação e Comunicação na Educação (TICE's) para os processos de ensino e aprendizagem do conceito de derivadas e suas aplicações em Cálculo Diferencial e Integral I, tendo como perspectiva a formação de futuros professores de Matemática. Sendo assim desenvolveu atividades investigativas, utilizando o software GeoGebra, com nove alunos matriculados na disciplina que se dispuseram a participar num período extraclasse. A atividade foi composta por quatro problemas adaptados de dois livros didáticos de cálculo e realizadas pelos alunos agrupados em dupla ou trio. Em cada problema, os licenciandos deveriam descrever uma ideia para a resolução e, a partir disso, buscar resolver o problema, sendo incentivados a refletir sobre os resultados obtidos nesse contexto de aprendizagem docente.

Para a pesquisadora, as atividades contribuíram para uma ressignificação dos conhecimentos dos alunos em relação às aplicações das derivadas, além de criar um ambiente de aprendizagem diferenciado e complementar à sala de aula, colaborando na constituição de um novo professor de matemática para a educação básica. A Figura 4, a seguir, apresenta um dos problemas resolvidos e discutidos em sala de aula pela pesquisadora. 
DOI: http://dx.doi.org/10.20396/zet.v25i3.8649991

Sua empresa foi contratada para fazer um projeto para captação de água da chuva em uma residência. Para isso, deve ser construido um tanque cilindrico para armazenar a água, com capacidade para 1.000 litros. Sua tarefa é determinar as dimensões que minimizarão o custo para construir esse reservatório.

a) Descreva, sucintamente, como você irá levar o custo em consideração para resolver o problema;

b) Escreva uma fömula $\mathrm{S}(\mathrm{x})$ para a área do tanque em função da medida $\mathrm{x}$ do raio da base; c) Construa o gráfico dessa função no GeoGebra;

d) Na barra de ferramentas do GeoGebra, clique em "Novo ponto" e sobre um ponto qualquer da curva; a seguir, clique em "Tangentes", sobre o ponto marcado e sobre a curva; clique em "Mover" e movimente o ponto; determine, então, o valor de x que toma a área minima e o valor da área minima, explicando suas conclusões.

Figura 4: Exemplo de Problema explorado no Ensino de Cálculo Fonte: Gonçalves (2012, p.61)

Resende (2007), mobilizada pela problemática do ensino da álgebra nos diferentes níveis de escolaridade e na formação de professores, teve como objetivo compreender a Teoria dos Números enquanto saber a ensinar e buscar elementos para ressignificar seu papel na licenciatura em matemática. Para isso analisou algumas propostas curriculares das disciplinas que tratam de Teoria dos Números, de doze universidades brasileiras, e dez livros didáticos escolhidos dentre os mais citados nos programas das disciplinas pesquisadas. Realizou ainda sete entrevistas semiestruturadas com professores e pesquisadores em Teoria dos Números ou em Educação Matemática.

Partindo das análises e das entrevistas, a pesquisadora apresenta, além de concepções sobre o papel da Teoria dos Números para a formação de professores, algumas características essenciais para a composição da ementa da disciplina e também quais conteúdos matemáticos podem ser abordados visando à formação do professor da escola básica. São elencados quatro pontos a serem considerados tanto na seleção de conteúdos quanto nos objetivos da disciplina (1) privilegiar os tópicos de teoria dos números presentes na educação básica, ou seja, os números naturais e os números inteiros; (2) considerar a teoria dos números como um espaço propício para o desenvolvimento de ideias matemáticas relevantes relativas aos números naturais e algumas também estendidas aos inteiros, presentes na matemática escolar; (3) considerar que a teoria dos números é um campo propício para uma abordagem mais ampla da prova, ultrapassando seu sentido tradicional, porque oferece ricas oportunidades para a exploração dos diferentes tipos de provas, permitindo ao licenciando perceber que a prova tem diferentes funções e que, no ensino, não deve ser compreendida da mesma forma que na pesquisa em matemática e (4) promover, no âmbito da disciplina, atividades de investigação matemática, porque permite a exploração de padrões e relações numéricas, o uso da recursão e da indução matemática, oportunizando o desenvolvimento das habilidades de conjecturar, generalizar, testar e validar as conjecturas.

Segundo a pesquisadora, essas potencialidades sustentam a concepção de uma disciplina que está sendo denominada Teoria Elementar dos Números, a qual tem como fonte o saber científico, mas também os saberes escolares e as demandas que o seu ensino 
DOI: http://dx.doi.org/10.20396/zet.v25i3.8649991

apresenta ao professor. Para a autora, constituem tópicos essenciais a serem abordados nesta disciplina os números inteiros em seus aspectos históricos, epistemológicos e procedimentais; a divisibilidade, números primos e equações diofantinas lineares. Seus objetivos e abordagens devem considerar que o conhecimento do conteúdo e o conhecimento pedagógico do conteúdo, a teoria e a prática devem estar presentes na sua constituição, como elementos indissociáveis e imprescindíveis. Esta pesquisa foi enquadrada nesta categoria por apresentar mais do que apenas concepções. Embora a autora não apresente formas efetivas de fazê-lo, com exemplos e situações que podem ser exploradas, são indicados caminhos para isso.

Após essa breve descrição de cada trabalho, passamos à análise e discussão de seus resultados, buscando fazer uma síntese dos aspectos emergentes. A proposta da sequência didática apresentada por Moreno (2010), aliada à maneira como ela foi desenvolvida, difere do ensino expositivo e formal, por propiciar momentos de reflexão e discussão entre os participantes e por levá-los a mobilizarem diversos conceitos, anteriormente abordados, na construção do conhecimento em questão.

Da mesma forma, a pesquisa de Procópio (2011) aponta que o trabalho em grupo, a discussão e a problematização, contribuem para o envolvimento dos alunos com os conceitos e atribuição de significados sobre os mesmos. Além disso, reafirma a particularidade do ensino de uma disciplina voltada à formação de professores, considerando saberes reconhecidos e validados na prática docente escolar como, por exemplo, diferentes modos de produção de significados para a Matemática e a proposição de problemas mais abertos, desmitificando a ideia da matemática como algo pronto e acabado.

Santos (2011) e Gonçalves (2012) apostam no uso de softwares no desenvolvimento de conceitos de geometria analítica e cálculo e concluem que as atividades relacionadas ao uso do software possibilitam a visualização de conceitos e propriedades, privilegiando a experimentação e a discussão entre os alunos sobre estes conceitos. Nesses contextos, os licenciandos vivenciam, na prática, um modo de ensinar Matemática, privilegiando o uso de recursos da tecnologia e, mais do que isso, aprendem não apenas implantá-los em suas aulas, mas vivenciam momentos que lhes mostram como estes recursos podem favorecer o ensino e a aprendizagem matemática de seus alunos.

A pesquisa de Resende (2011) parece propor uma abordagem para a disciplina de Teoria dos Números, a qual tende a propiciar uma aprendizagem que vai além do conhecimento dos processos formais dos números, dando lugar à discussão e análise crítica, avaliando seus limites e possibilidades enquanto objetos de ensino, favorecendo a construção de uma autonomia ao professor para explorá-los e problematizá-los de forma pedagogicamente mais significativa, como destacam Moreira e David (2005).

As cinco pesquisas apontam quais conteúdos acreditam que deveriam ser abordados nas disciplinas investigadas. De modo geral, estas investigações trazem contribuições sobre a maneira como os conceitos podem ser abordados de forma a contribuir com o a prática profissional do professor. Essa contribuição vai ao encontro do que Fiorentini (2005) discute ao defender que essas disciplinas ensinam, além do conteúdo, modos pertinentes ou 
DOI: http://dx.doi.org/10.20396/zet.v25i3.8649991

inadequados de ensinar, de ser professor e de estabelecer relação com a matemática no contexto de ensino e aprendizagem.

Os cenários diferenciados, apresentados pelas pesquisas que abordam o uso de softwares e práticas como a problematização e discussão de resultados, reflexão e ressignificação de conceitos e propriedades, se aproximam das práticas reflexivas, investigativas e colaborativas que, de acordo Passos et. al. (2006), promovem o desenvolvimento profissional do professor.

\section{(b) Foco em como ensinar}

Freitas (2006), no contexto da disciplina Geometria Plana e Desenho Geométrico, investigou como os estudantes do curso de licenciatura em Matemática participam e respondem à experiência de uma disciplina de formação matemática com uma proposta que privilegia o registro escrito de seus pensamentos e ideias. Foram propostas atividades que exploravam o uso da escrita, associada à utilização de tecnologias de informação e comunicação e ao desenvolvimento de projetos. A pesquisadora analisou produções dos licenciandos como autobiografias, atividades desenvolvidas na disciplina (cartas, bilhetes, relatórios, projetos), entrevistas semi-estruturadas, questionários e textos de mensagens eletrônicas.

A proposta da disciplina envolvia atividades semanais desenvolvidas em dois ambientes: o das aulas teóricas, em sala de aula regular, e o das aulas práticas, em laboratório de informática nas quais era priorizado o uso do software Tabulae. Além desses dois ambientes, os alunos deveriam realizar, em duplas, um projeto de aplicação do que iriam aprender, cujas versões seriam apresentadas para discussão em sala durante o semestre.

A avaliação foi baseada nas atividades de laboratório semanais (individuais) e no projeto (em duplas), com datas predefinidas para apresentação do pré-projeto para discussão, entrega do texto escrito do projeto e apresentação oral do mesmo. Desde o início, a professora, que trabalhava em parceria com a pesquisadora, deixou claro que a avaliação era distribuída ao longo do processo, valorizando o registro do raciocínio por meio da linguagem escrita em vez de provas formais.

O projeto a ser desenvolvido em duplas tinha por objetivos: criar uma proposta de atividade de laboratório, para alunos do ensino fundamental ou médio, envolvendo a geometria; registrar, por escrito, o processo de criação, o material produzido e uma solução para a proposta apresentada; apresentar oralmente o material desenvolvido, compartilhando as ideias com a classe.

Para Freitas (2006), a escrita na disciplina de Geometria, associada à utilização de tecnologias de informação e comunicação e ao desenvolvimento de projetos contribuiu, de um lado, para promover processos metacognitivos sobre a aprendizagem da Matemática e, de outro, para produzir outros sentidos à Matemática - seus conceitos e processos. Além disso, a pesquisadora ressalta que a experiência descrita influenciou a prática futura dos professores, pois estes passaram também a explorá-la didático-pedagogicamente com seus alunos. 
DOI: http://dx.doi.org/10.20396/zet.v25i3.8649991

Richit (2005), por sua vez, propôs-se a descrever e analisar uma experiência de Trabalho com Projetos em Geometria Analítica, desenvolvida com o auxílio do software de Geometria Dinâmica Geometricks. A experiência foi direcionada a oito alunos de licenciatura em matemática, em recuperação na disciplina. Os objetivos foram promover a construção de saberes específicos desta área do conhecimento e contribuir para que os sujeitos envolvidos pudessem desenvolver saberes de uso pedagógico do software, visando favorecer a formação destes futuros professores de matemática.

A cada dupla foi proposta a escolha de tópicos da Geometria Analítica e a elaboração de, no mínimo, cinco atividades que abordassem aqueles conceitos por meio do uso do software Geometricks. A realização das atividades foi dividida em módulos, incluindo a familiarização com o software, investigação e discussão dos conceitos de Geometria Analítica abordados pelas duplas, elaboração de atividades envolvendo os conteúdos selecionados, organização do projeto e discussão coletiva posterior à apresentação das mesmas, analisando-se a viabilidade e contribuição aos processos de ensino e aprendizagem desta disciplina.

Além disso, foram promovidas, também, sessões de discussão de conceitos, demonstração de propriedades e equações, assim como resolução de problemas propostos em livros didáticos, visando retomar tópicos deficitários e formalizar as proposições apresentadas nas atividades, priorizando sempre a representação gráfica e a passagem desta para a representação algébrica a partir das propriedades visualizadas.

A pesquisadora conclui que a combinação do trabalho com projetos e o uso de software de geometria dinâmica, tendo por contexto a Geometria Analítica, mostrou-se uma estratégia pedagógica favorável à formação inicial docente em matemática no que concerne à construção de saberes específicos desta área do conhecimento e contribuiu para que os sujeitos envolvidos pudessem desenvolver saberes de uso pedagógico do software Geometricks. Ainda, para Richit (2005), há necessidade de desenvolver no futuro professor competências necessárias para que incorpore as tecnologias informáticas à sua prática posterior, à medida que o seu processo de formação promova a utilização destes recursos no contexto das experiências educacionais na licenciatura.

Campos (2007), por outro lado, buscou compreender como um Projeto Pedagógico intitulado "Trabalho de Projetos e Educação Estatística na Universidade", desenvolvido de forma concomitante à disciplina Estatística e Probabilidade, pode contribuir para o desenvolvimento profissional dos estudantes do curso de Matemática.

Os grupos participantes tinham que formular uma questão ou determinar um tema de investigação, definir os instrumentos de coleta de dados, organizar e escolher a representação mais adequada para comunicá-los. Em seguida, houve a preparação do ambiente para a escolha dos temas, planejamento das atividades, problematização e por último, a síntese das informações. Para organização dos dados, os alunos utilizaram o software Excel e, para que aprendessem a utilizá-lo em favor do projeto em desenvolvimento, foram propostos momentos de familiarização e exploração. 
DOI: http://dx.doi.org/10.20396/zet.v25i3.8649991

Para Campos (2007), a conexão entre o conteúdo específico da disciplina Estatística e Probabilidade, com situações de aplicação à prática escolar, possibilita a articulação dos diferentes conceitos estatísticos entre si e com outras áreas do conhecimento. Além disso, promove a indissociabilidade entre ensino e pesquisa, tendo como suporte o trabalho com projetos fundamentados em um trabalho colaborativo. Quanto às contribuições à prática pedagógica do professor, a pesquisadora constata que este tipo de projeto "permite que o professor adote uma postura educativa com ênfase na investigação do saber estatístico, onde se aprende Estatística fazendo Estatística" (p.105) de modo que o saber estatístico deixa de ser um saber de fórmulas e algoritmos para ser um saber em ação.

Por fim, a pesquisadora conclui que os alunos desenvolveram saberes relativos ao ensino com pesquisa; saberes relacionados ao trabalho colaborativo; saberes referentes à utilização de recursos computacionais; saberes relativos à metodologia de projetos e saberes para investigação dentro de métodos estatísticos, o que contribui para a vida profissional dos alunos.

Pinheiro (2008), entretanto, buscou analisar a mediação realizada em sala de aula para a construção do raciocínio geométrico de futuros professores de matemática matriculados na disciplina de Desenho Geométrico. O trabalho foi desenvolvido com um professor que ministrou a disciplina na licenciatura com base no uso de régua e compasso. O professor regente possuía formação inicial de Engenharia Civil e, há 32 anos, trabalhava como professor de Geometria, possuindo domínio de diversas técnicas de desenhos, e costumava apresentar aos alunos o passo a passo e modelos consistentes.

No começo e no fim da disciplina, foi proposto pelo professor, aos futuros professores, vários exercícios com o objetivo de analisar o nível do conhecimento conceitual da Geometria Plana, antes e depois destas aulas. Segundo Pinheiro (2008), durante a disciplina o formador não trabalhou com conceitos e demonstrações teóricas, mas estava sempre questionando e instigando os alunos a refletir e discutir o que estavam aprendendo. Às vezes ele fazia as construções na lousa, explicando aos alunos; outras vezes, os alunos guiavam verbalmente a construção; e, ainda, havia momentos em que os alunos e professor iam pensando-a coletivamente.

O pesquisador discute que, nessas aulas, a ação docente estava em constante construção por meio das interações entre formador e futuros professores, constituindo uma prática com base no conteúdo a ser trabalhado, diferenciando-se da metodologia tradicional de ensino da matemática, cujos conteúdos costumam ser apresentados numa sequência lógica e estanque: dedução formal, exercícios resolvidos pelo professor e exercícios propostos a serem resolvidos pelos alunos. Entretanto, Pinheiro questiona e problematiza a pertinência dessa prática formativa e relação com a matemática baseado na formação do engenheiro, tendo em vista a formação do professor de matemática. $\mathrm{O}$ formador engenheiro, por exemplo, carrega o domínio da técnica, mas muitas vezes não discute a matemática envolvida nos processos, não privilegiando assim a argumentação e exploração das construções. Para o pesquisador, é necessário promover o diálogo e a reflexividade com os estudantes de licenciatura a partir das construções propostas, para que eles possam aprender algo Zetetiké, Campinas, SP, v.25, n. 3, set./dez.2017, p.515-533 
DOI: http://dx.doi.org/10.20396/zet.v25i3.8649991

importante à sua futura vida profissional como professores de matemática e que vai além do raciocínio puramente geométrico.

Novamente, após a descrição das pesquisas, passamos para a discussão e síntese dos resultados e aspectos emergentes. O foco da pesquisa de Freitas (2006) foi problematizar e investigar os modos de ensinar e aprender geometria na licenciatura, tendo em vista a futura prática profissional do professor, sem, entretanto, detalhar os conteúdos desse processo de formação.

Uma das atividades introdutórias ao estudo da geometria dinâmica, em diferentes ambientes, relatada por Freitas (2006) foi, por exemplo, a divisão em três partes iguais de um quadrado e posteriormente de um retângulo. Embora fosse uma atividade bastante óbvia e elementar, principalmente a partir de desenhos sobre o papel, a construção de uma prova/demonstração para essa divisão, em linguagem escrita formal e não formal, foi, entretanto, altamente desafiante, problematizadora e formativa para os futuros professores, principalmente a partir de dobraduras e do uso do software Tabulae. Essa prática formativa no contexto da formação inicial de professores delineia, portanto, um modo de ensinar e aprender muito diferente do tradicionalmente adotado. A forma e a dinâmica de trabalho propostas e desenvolvidas pela disciplina contribuiu para desenvolver a habilidade de explicar, argumentar e comunicar que são competências e saberes importantes para o professor que irá trabalhar com alunos do Ensino Fundamental e Médio.

No contexto apresentado por Richit (2005), os licenciandos prepararam tarefas e situações-problema para alunos da Educação Básica a partir de tópicos de Geometria Analítica que estavam estudando na disciplina. Esta vivência viabilizou um modo de estabelecer conexão entre a formação inicial e a futura prática docente do licenciando (Moreira e David, 2005), de modo que, além de aprender os tópicos, houvesse reflexão e ensaios sobre como ensiná-los aos alunos na Educação Básica. Campos (2007), por sua vez, mostrou que o Trabalho com Projetos pode promover o desenvolvimento de diversos saberes relacionados à pesquisa, colaboração, investigação e uso de software, e articular diferentes conceitos estatísticos entre si e com outras áreas do conhecimento, de modo que os alunos podem aprender Estatística enquanto a fazem, a utilizam e explicam seus resultados aos outros alunos.

A pesquisa de Pinheiro (2008) mostrou que a disciplina de Geometria precisa promover o desenvolvimento do raciocínio algébrico e geométrico, buscando explorar as relações entre ambos, fornecendo uma aprendizagem ampla da geometria e também que, embora a mediação do professor seja um fator que contribui para a construção deste raciocínio, a exploração, argumentação e problematização da matemática envolvida se faz necessária para que o saber em questão seja significativo ao futuro professor.

As pesquisas apresentadas, ao focarem em processos de desenvolvimento das disciplinas, como o uso de tecnologias, da escrita, de trabalhos com projetos e de mediação docente, e analisar quais são as contribuições para o ensino e aprendizagem de Matemática, mostram que formas de organização que privilegiem o trabalho colaborativo, as práticas 
DOI: http://dx.doi.org/10.20396/zet.v25i3.8649991

investigativas (abordadas quando os pesquisadores destacam a exploração, a argumentação e a problematização de conceitos) e práticas reflexivas (Passos et. al., 2006) contribuem para a formação do licenciando e trazem implicações para sua prática docente, como no caso de Freitas (2006) que afirma que os licenciandos passaram, quando se formaram, a explorar a escrita discursiva (formal e não-formal) no ensino da Matemática com seus alunos na escola básica e de Richit (2005) ao afirmar que os licenciandos aprenderam a fazer o uso pedagógico do software.

Esses resultados nos levam a refletir sobre o papel do professor formador que leciona disciplinas de conteúdo matemático, considerando que as contribuições destas pesquisas estão relacionadas ao modo como eles organizam as disciplinas e a lecionam. Entendemos que atuação do formador interfere na formação e prática dos licenciandos. Um exemplo é a pesquisa de Pinheiro (2008), na qual fica evidente que a formação do professor da disciplina em engenharia se reflete em algumas lacunas na formação dos licenciandos, deixadas pela prática desse formador, ao não estimular a argumentação e exploração das construções geométricas propostas.

\section{Algumas considerações finais}

Esta pesquisa buscou, em um primeiro momento, mapear as teses e dissertações brasileiras que tomam como foco de estudo as disciplinas de conteúdo matemático dos cursos de Licenciatura e, em um segundo momento, analisar e discutir como elas têm contribuído para compreender o campo da formação inicial do professor de matemática. Para tentar responder à questão de investigação "Que indícios trazem estas pesquisas sobre o modo como as disciplinas de conteúdo matemático são desenvolvidas, tomando como referência a prática profissional efetiva dos professores da educação básica?", discutimos alguns resultados e pontos emergentes que consideramos importantes à formação matemática do professor de matemática.

Dos 15 trabalhos que compõem o corpus inicial, analisamos um grupo de nove trabalhos sendo duas teses de doutorado e sete dissertações de metrado, que apresentam propostas de conteúdo ou práticas inovadoras no contexto das disciplinas de formação matemática investigadas.

Os resultados apresentados por estas pesquisas apontam que as disciplinas de conteúdo matemático necessitam ser desenvolvidas a partir de práticas que problematizam os conceitos abordados e levem os licenciandos a refletir, discutir, explorar e problematizar a Matemática, tendo em vista seu ensino e aprendizagem na escola básica. Essas práticas, que diferem daquelas privilegiadas no ensino expositivo e formal dos conceitos, apresentam contribuições tanto para a formação matemática dos licenciandos, quanto para prática profissional deste como futuro professor.

O uso de softwares, abordados por cinco das pesquisas mapeadas, tem se mostrado uma ferramenta potencial para o desenvolvimento de disciplinas de conteúdo matemático, possibilitando manipulação, visualização e exploração de conceitos de forma mais dinâmica e 
DOI: http://dx.doi.org/10.20396/zet.v25i3.8649991

atrativa aos licenciandos, e interferindo em seu modo de ver e explorar o ensino da Matemática.

O alcance de tais resultados para a formação de professores, entretanto, depende diretamente da atuação do professor formador nas disciplinas de conteúdo matemático, uma vez que as pesquisas mostraram influências de sua prática docente para a formação e constituição do professor em seu processo formativo.

Além de investir na formação dos formadores que atuam nas disciplinas de formação matemática, há necessidade de promover também mudanças no cenário atual dos cursos de licenciatura de modo que as disciplinas de matemática possam promover e problematizar uma formação matemática relevante e fundamental à futura prática profissional do professor de matemática na escola básica em uma perspectiva que não seja apenas formal e procedimental, mas conceitual e voltada à aprendizagem de conhecimentos fundamentais e específicos da docência em matemática.

Embora as pesquisas aqui mapeadas e analisadas apresentem contribuições para o desenvolvimento de disciplinas de conteúdo matemático e tenham avançado em relação às problemáticas apresentadas, fica evidente que são necessárias muito mais investigações que foquem no conhecimento matemático do futuro professor e que estabeleçam relações mais claras e consistentes entre os conteúdos que o licenciando aprende e aqueles que futuramente irá ensinar.

\section{Referências}

Brasil (2002). Ministério da Educação. Conselho Nacional de Educação. Parecer CNE/CES 1.302/2001. Brasília. Retirado em 02 de março, 2016, de: http://planalto.gov.br/cne/arquivos/pdf/ces1302.pdf.

Ferreira, N. S. (2002). As pesquisas denominadas "estado da arte". Educação \& Sociedade, $79,257-272$.

Fiorentini, D. (2005). A formação Matemática e didático-pedagógica nas Disciplinas da Licenciatura em Matemática, Revista de Educação PUC-Campinas, Campinas, 8, 107 115.

Fiorentini, D., Passos, C. L. B., \& Lima, R. C. R. (Org.)(2016). Mapeamento da pesquisa acadêmica brasileira sobre o professor que ensina Matemática: Período 2001 a 2012. Campinas, FE-Unicamp, Retirado em 25 de julho, 2017, de: https://www.fe.unicamp.br/pf-fe/pagina_basica/58/e-book-mapeamento-pesquisapem.pdf.

Grilo, J. S., Barbosa, J. C., \& Luna, A. V. (2015). Repercussões de disciplinas específicas na ação do professor de matemática da educação básica: Uma revisão sistemática, Educação Matemática e Pesquisa, 17(1), 04-24.

Manrique, A. L. (2009). Licenciatura em Matemática: formação para a docência x formação específica. Educação Matemática Pesquisa, 11(3), 515-534. 
DOI: http://dx.doi.org/10.20396/zet.v25i3.8649991

Moreira, P. C., \& David, M. M. (2005). A formação matemática do professor. São Paulo: Autêntica, $1^{\mathrm{a}}$ ed.

Nunes, C. M. F. (2001). Saberes docentes e formação de professores: Um breve panorama da pesquisa brasileira. Educação e Sociedade, 74, 27-42.

Passos, C. L., Nacarato, A. M., Fiorentini, D., Miskulin, R. G. S., Grando, R. C., Gama, R. P., \& Melo, M. V. (2006). Desenvolvimento profissional do professor que ensina Matemática: Uma meta-análise de estudos brasileiros. Quadrante, 25(1-2), 193-219.

\section{Apêndice 1: Referências dos trabalhos que compõem o corpus de análise geral da pesquisa}

Bolognezi, R. A. L. (2006). A Disciplina de Análise Matemática na Formação de Professores de Matemática para o Ensino Médio. Dissertação de Mestrado em Educação. Curitiba: Pontífice Universidade Católica.

Campos, S. G. V. B. (2007). Trabalho de projetos no processo de ensinar e aprender estatística na universidade. Dissertação de Mestrado em Educação. Uberlândia: Universidade Federal de Uberlândia.

Costa, A. (2007). A educação estatística na formação do professor de matemática. 2007. Dissertação de Mestrado em Educação. Itatiba: Universidade de São Francisco.

Freitas, M. T. M. (2006). A escrita no processo de formação contínua do professor de matemática. Tese de doutorado em educação. Campinas: Universidade Estadual de Campinas.

Gonçalves, D. C. (2012). Aplicações de Derivadas no Cálculo I: Atividades Investigativas utilizando o GeoGebra. Mestrado Profissional em Educação Matemática. Ouro Preto: Universidade Federal de Outro Preto.

Marin, D. (2009). Professores de matemática que usam a tecnologia de infgeormação e comunicação no ensino superior. Dissertação de Mestrado em Educação Matemática. Rio Claro: Universidade Estadual Paulista.

Martines, P. T. (2012). O papel da disciplina de análise segundo professores e coordenadores. Dissertação de Mestrado em Educação Matemática. Rio Claro: Universidade Estadual Paulista.

Mondini, F. (2009). Modos de conceber a álgebra em cursos de formação de professores de matemática. Dissertação de Mestrado Acadêmico em Educação Matemática. Rio Claro: Universidade Estadual Paulista.

Moreno, M. M. B. (2010). Ensino e aprendizagem de estatística com ênfase na variabilidade: um estudo com alunos de um curso de licenciatura em Matemática. Dissertação de mestrado em Ensino de Matemática. São Paulo: Pontífice Universidade Católica. 
DOI: http://dx.doi.org/10.20396/zet.v25i3.8649991

Pinheiro, A. C. M. (2008). A mediação docente na construção do raciocínio geométrico de alunos da licenciatura em matemática na disciplina desenho geométrico. Dissertação de Mestrado em Educação. Fortaleza: Universidade Estadual do Ceará.

Procópio, R. B. (2011). Geometria como um curso de serviço para a Licenciatura em Matemática: uma leitura da perspectiva do modelo dos campos semânticos. Dissertação de Mestrado em Educação Matemática. Juiz de Fora: Universidade Federal de Juiz de Fora.

Reis, F. da S. (2001). A tensão entre rigor e intuição no ensino de cálculo e análise: a visão de professores-pesquisadores e autores de livros didáticos. Doutorado em Educação Matemática. Campinas: Universidade Estadual de Campinas.

Resende, M. R. (2007). Re-significando a Disciplina Teoria dos Números na Formação do Professor de Matemática na Licenciatura. Tese de Doutorado em Educação. São Paulo: Pontífice Universidade Católica.

Richit, A. (2005). Projetos em geometria analítica usando software de geometria dinâmica: repensando a formação inicial docente em Matemática. Dissertação de Mestrado Acadêmico em Educação Matemática. Rio Claro: Universidade Estadual Paulista.

Santos, I.N. (2011). Explorando conceitos de Geometria Analítica Plana utilizando Tecnologias da Informação e Comunicação: uma ponte do Ensino Médio para o Ensino Superior construída na formação inicial de Professores de Matemática. Mestrado Profissional em Educação Matemática. Ouro Preto: Universidade Federal de Outro Preto. 